\title{
Fluid management in perioperative and critically ill patients
}

\author{
Dongho Kang, Kyung Yeon Yoo \\ Department of Anesthesiology and Pain Medicine, Chonnam National University Hospital, Chonnam National University Medical School, Gwangju, Korea
}

Fluid therapy to restore and/or maintain tissue perfusion may affect patient outcomes in perioperative, emergency, and intensive care. Kinetic analyses and outcome-oriented studies have provided more insight into fluid management. Crystalloids are slowly distributed to the interstitial space, and the efficiency (proportion of infused fluid retained in the bloodstream) is 50\%-75\% as long as infusion continues and may increase up to 100\% when the arterial pressure has decreased. Elimination of the infused fluid during general anesthesia and surgery is very slow, amounting to only 10\%-20\% compared with that in conscious patients. When the endothelial glycocalyx layer is degraded in sepsis or trauma-induced systemic inflammation, turnover of colloids and crystalloids is accelerated and the efficiency is reduced, which may lead to tissue edema, inflammation, poor wound healing, and organ dysfunction. Balanced crystalloids are pragmatic initial resuscitation fluids and improve patient outcomes compared to saline ( $0.9 \%$ sodium chloride). Albumin may be beneficial, but other synthetic colloids appear to increase the risk of acute kidney injury and death among patients in the intensive care unit. Fluid kinetics is likely to change based on patient physiological conditions (e.g., general anesthesia, surgery, stress, dehydration, blood pressure, or inflammation) and fluid types. To maximize efficacy and minimize iatrogenic side effects, fluids should be prescribed based on individual patient factors, disease states, and other treatment remedies.

Key Words: colloids; crystalloid solutions; fluid therapy; glycocalyx; intensive care

\section{INTRODUCTION}

Intravenous (IV) fluid therapy is essential and lifesaving in critically ill patients and in individuals undergoing major surgery. The rates of distribution and elimination of infused fluid are influenced by factors such as general anesthesia [1], stress, dehydration [2,3], age, and arterial pressure [4]. For instance, $5 \%-10 \%$ of infused volume is excreted within 2 hours during general anesthesia and surgery $[5,6]$, while $75 \%-90 \%$ is excreted within 2 hours in a conscious state $[2,3]$. The efficiency (proportion of infused fluid retained in the bloodstream) is $50 \%$ $75 \%$ as long as infusion continues, although this fraction may increase up to $100 \%$ when the arterial pressure has decreased by $20 \%-30 \%$, as in acute hemorrhage or during induction of anesthesia [5]. Kinetic analyses [1,6-9] and outcome-oriented studies [10-14] have provided more insight into how crystalloid infusions should be managed. Infusion of crystalloids in patients undergoing surgery under general anesthesia has a much better short-term effect on plasma volume expansion than previously believed.

\section{Review Article}

Received: October 4, 2019

Revised: November 5, 2019

Accepted: November 5, 2019

Corresponding author

Kyung Yeon Yoo

Department of Anesthesiology and

Pain Medicine, Chonnam National

University Hospital, Chonnam

National University Medical School,

42 Jebong-ro, Dong-gu, Gwangju

61469, Korea

Tel: +82-62-220-6893

Fax: +82-62-232-6294

E-mail: kyyoo@jnu.ac.kr

Copyright () 2019 The Korean Society of Critical Care Medicine

This is an Open Access article distributed under the terms of Creative Attributions Non-Commercial License (http:// creativecommons.org/li-censes/by-nc/4.0/) which permits unrestricted noncommercial use, distribution, and reproduction in any medium, provided the original work is properly cited. 
Recently, the role of the endothelial glycocalyx layer (EGL) in microvascular permeability has attracted much attention. The EGL is disrupted (shed) in various pathophysiological states such as sepsis, ischemia-reperfusion injury, hemorrhagic shock, trauma, and major abdominal surgery or with rapid infusion of fluid (especially saline) [15-18]. Under these circumstances, transcapillary flow is increased, allowing protein-rich plasma to move across the vascular wall, contributing to development of hypovolemia, interstitial edema, and organ dysfunction [17-19].

The composition of IV fluid may also affect organ function and patient outcomes. A large volume of saline ( $0.9 \%$ sodium chloride) has been associated with hyperchloremic acidosis [20,21] and acute kidney injury (AKI) [22-25]. Saline was also associated with a greater risk of AKI and death in sepsis [14]. In recent randomized controlled trials, saline was associated with increased incidence of death, new renal replacement therapy, and persistent renal dysfunction during critical [10] or acute illness compared with balanced crystalloids [11]. On the other hand, hydroxyethyl starch (HES) showed nephrotoxic effects in sepsis and in intensive care settings [26,27]; however, negative effects were not observed in a surgical context $[28,29]$.

The optimal composition, dose, and rate of fluid administration have not been well established based on scientific evidence. Therefore, we hereby review the previous documents regarding the fluid kinetics and the fluid composition to help clinicians choose proper type and amount of resuscitation fluids in various clinical scenarios, especially in the perioperative and critical care settings.

\section{PHYSIOLOGY OF BODY FLUID COMPARTMENT AND FLUID HOMEOSTASIS}

\section{Body Water Distribution}

In a $70-\mathrm{kg}$ male, the total amount of body water is approximately $42 \mathrm{~L}$ ( $60 \%$ of body weight); approximately $28 \mathrm{~L}$ of which are located inside the cells (intracellular fluid, $40 \%$ of body weight), while the remaining $14 \mathrm{~L}$ are outside the cells (extracellular fluid [ECF], $20 \%$ of body weight). The ECF is further compartmentalized into interstitial fluid (11 L) and plasma (3 L).

\section{Endothelial Glycocalyx Layer}

The EGL is an approximately 2 - $\mu \mathrm{m}$-thick, membrane-bound, sponge-like mesh consisting of glycoproteins and proteoglycans. The EGL covers the entire vascular lumen, occupying 700-1,000 ml of the intravascular space [30]. The soluble com-

\section{KEY MESSAGES}

- Crystalloids are more effective plasma volume expanders than previously believed during general anesthesia and intensive care.

- The endothelial glycocalyx layer plays an important role in microvascular permeability.

- The current trend in perioperative and critical care settings is to choose balanced crystalloids over saline or hydroxyethyl starch for volume replacement.

ponents of the plasma, mainly albumin, are embedded within the EGL meshwork. The combination of the meshwork and the trapped proteins opposes transcapillary filtration and has a regulatory role in leukocyte and platelet adhesion on the endothelial surface [16]. Recently, circulating levels of the EGLshedding biomarkers heparan sulfate, syndecan-1, and hyaluronic acid were evaluated in vulnerable clinical scenarios as diagnostic markers and therapeutic targets (Figure 1) [17,18].

The EGL excludes molecules larger than $70 \mathrm{kDa}$. However, plasma proteins may leak into the interstitium through a relatively small number of large pores (i.e., capillary leaks), which are responsible for increased transcapillary flow (Jv) observed in the early stage of inflammation [31]. The transcapillary escape rate of albumin to the tissues is an index of vascular permeability and is normally $5 \%$ of the plasma albumin per hour. The escape rate can double during surgery and increase by up to more than four-fold in septic shock [19].

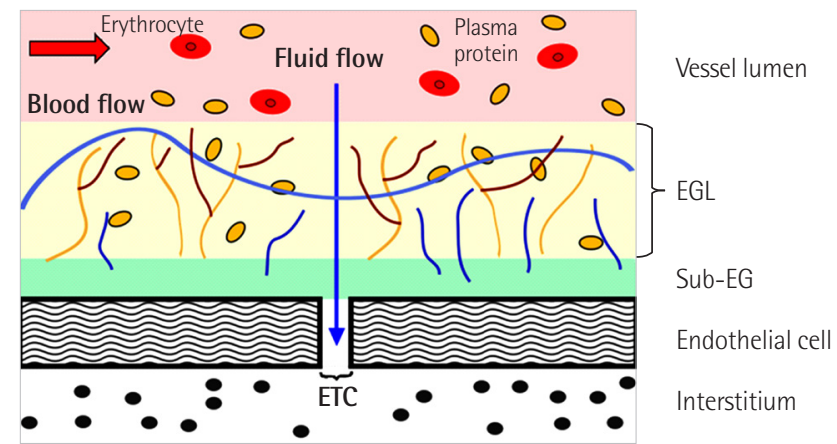

Figure 1. Schematic presentation of endothelial glycocalyx layer $(E G L)$ and surrounding structures. The EGL is a meshwork composed of inner membrane-bound proteoglycans (e.g., syndecan, glypican) and outer glycosaminoglycans (e.g., hyaluronan, heparan sulfate, chondroitin sulfate) embedded with plasma proteins (e.g., albumin) on endothelial cells and is a key determinant of capillary permeability in various vascular organ systems. Sub-EG: subglycocalyceal space; ETC: endothelial intercellular clefts. 


\section{Capillary Tissue Fluid Dynamics}

The fundamental principle governing the transcapillary fluid exchange between plasma and interstitial space was established by Starling in 1896 [32]. According to the classic Starling principle, Jv depends on a balance between hydrostatic and oncotic pressure gradients across the capillary wall; the fluid is squeezed out by a dominant hydrostatic pressure to the interstitium at the arteriolar portion, and almost the same amount of fluid is absorbed back by osmotic attraction at the venular end. However, at the beginning of this century, the effects of oncotic pressure on Jv were determined to be too weak to reverse the hydrostatically-driven movement of fluid at the venular end [33].

Levick and Michel [31] revised the Starling equation by incorporating the EGL, where $\mathrm{Jv}=\mathrm{Kf}\left([\mathrm{Pc}-\mathrm{Pis}]-\sigma\left[\pi_{\mathrm{c}}-\pi_{\mathrm{sg}}\right]\right)$ : Kf, hydraulic conductance; Pc, capillary hydrostatic pressure; Pis, interstitial hydrostatic pressure; $\sigma$, osmotic reflection co-efficient; $\pi_{\mathrm{c}}$, oncotic pressure on plasma-side of ESL; and $\pi_{\mathrm{sg}}$, oncotic pressure in sub-glycocalyx space. The EGL separates plasma from the sub-glycocalyx space containing protein-poor fluid, thereby producing a negligible oncotic pressure $\left(\pi_{\mathrm{sg}}\right)$ that is an important determinant of Jv (Figure 1). The oncotic pressure difference across the EGL opposes but does not reverse Jv through venous capillaries and venules. Consequently, the fluid leaks into the interstitium from the capillaries and from venules under a dominant hydrostatic pressure gradient, and transcapillary absorption is not likely to occur (the "no absorption" rule). Most of the filtrate then returns to circulation via the lymphatic system [34]. This concept suggests that all infused fluids can accumulate dose-dependently in the interstitial space and contribute to formation of interstitial edema, particularly under inflammatory conditions in which resuscitation fluids are used excessively.

\section{FLUID DISTRIBUTION KINETICS DURING ANESTHESIA AND SURGERY}

In volume kinetic studies, crystalloids have been shown to distribute throughout the ECF space with a half-life of approximately 8 minutes, requiring 30 minutes to equilibrate under normal physiological conditions [35]. The slow distribution renders crystalloids a fairly good plasma volume expander with an efficiency of $50 \%-75 \%$ as long as infusion is continued [5].

The distribution rate of the infused fluid is context-sensitive [9]. The infused crystalloids are initially distributed in the intravascular space. When capillary pressure (or transendothelial pressure difference) is higher than normal, the crystalloids increases Jv more than does the same volume of colloids. In contrast, when capillary pressure is low, such as during acute hypotension (arterial pressure reduction greater than $20 \%-30 \%$ ) after induction of anesthesia, in hypovolemia, or in septic shock, Jv declines to close to zero. Consequently, distribution of the infused fluid to the interstitial space is arrested, with fluid efficiency reaching almost $100 \%$ [34]. Capillary refill from interstitial fluid is also likely to occur ("autotransfusion"), although it lasts only for a few minutes when the capillary pressure is abruptly reduced by a large amount of acute blood loss [31].

During surgery and anesthesia, elimination of infused fluid amounts to approximately $10 \%-20 \%$ of that in a conscious state [9]. Surgery and stress significantly alter the fluid balance, leading to fluid retention, probably via modulation of adrenergic activity and levels of aldosterone, antidiuretic hormone, and renin [5]. Isoflurane alone lowers renal clearance for crystalloids by $50 \%$ [1]. Renal clearance is approximately only $7 \mathrm{ml} / \mathrm{min}$ during laparoscopic surgery [6], while it is 60$110 \mathrm{ml} / \mathrm{min}$ in conscious volunteers [36]. The half-life (T1/2) of crystalloids is as much as 10 times longer during surgery under general anesthesia, eliciting an augmented plasma volume expansion with a concomitant risk of peripheral fluid accumulation (Table 1) [5]. Old age and low blood pressure further reduce elimination during surgery, thereby enhancing fluid overload [4].

In addition, $\mathrm{T} 1 / 2$ differs according to type of crystalloid and sex and is longer for saline (110 minutes) than acetated (56 minutes) and lactated Ringer's (50 minutes) solutions [36]. The time to the first void for saline is twice as long as for Ringer's lactate [37] and three times as long for $5 \%$ glucose $[5,38]$. The longer $\mathrm{T} 1 / 2$ of saline can be attributed to renal vasoconstriction associated with high chloride content [39]. In addition, Ringer's acetate showed a longer T1/2 in males than in females (38 minutes vs. 24 minutes) [40]. However, unlike crystalloids, the $\mathrm{T} 1 / 2$ for plasma volume expansion during surgery under general anesthesia (without hypotension) with colloids was not different from that of the volunteers [41].

One unanswered question regarding fluid kinetics during anesthesia and surgery is why crystalloids require 25-30 minutes for complete distribution into the interstitium despite the small size of the electrolytes $(0.2 \mathrm{~nm})$ relative to the capillary pore (approximately $6 \mathrm{~nm}$ ). Another question is why the fluid accumulated intraoperatively in the interstitium is not readily excreted after surgery, while that administered postoperatively is promptly eliminated [42]. In fact, several days are required for crystalloids administered intraoperatively to be completely excreted from the body [43]. 
Table 1. Half-life (T1/2) of crystalloids in different patient conditions during the perioperative period

\begin{tabular}{|c|c|c|c|c|}
\hline Period & Study condition & Fluid type & $\mathrm{T} 1 / 2$ (min) & Female:male \\
\hline \multirow[t]{3}{*}{ Awake volunteer } & Well hydrated & Ringer's acetate & $23(12-37)$ & $0: 20$ \\
\hline & Volunteers & Ringer's acetate & $40(31-53)$ & $0: 8$ \\
\hline & Dehydrated & Ringer's acetate & $76(57-101)$ & $0: 20$ \\
\hline \multirow[t]{3}{*}{ Preoperative } & Before Cesarean section & Ringer's acetate & $175(115-322)$ & $10: 0$ \\
\hline & Patient 2 to 3 hours before surgery & Ringer's acetate & $23(8-61)$ & 10:19 \\
\hline & Patient immediately before surgery & Ringer's lactate & 169 (76-455) & $8: 7$ \\
\hline \multirow[t]{4}{*}{ Intraoperative } & Thyroid surgery & Ringer's acetate & $327(144-642)$ & $14: 1$ \\
\hline & Laparoscopic cholecystectomy & Ringer's acetate & $268(88-1,366)$ & $12: 0$ \\
\hline & Open abdominal surgery & Ringer's lactate & $172(75-424)$ & $5: 5$ \\
\hline & Gynecological laparoscopy & Ringer's lactate & $346(165-801)$ & $20: 0$ \\
\hline Postoperative & 4 Hours after laparoscopy & Ringer's lactate & $17(13-29)$ & $15: 5$ \\
\hline
\end{tabular}

Adapted from Hahn and Lyons. Eur J Anaesthesiol 2016;33:475-82 [5]. T1/2 are presented as median (25-75th percentile range). Most infusions were $25 \mathrm{ml} / \mathrm{kg}$ and infused over 30 minutes.

The interstitium is filled with a fine gel fiber matrix (i.e., proteoglycan filament); thus, its compliance is low due to the viscoelastic properties of the fibers in the meshwork [35]. The elastic proteoglycan filaments may prevent fluid from flowing easily through the gel, resulting in slow fluid distribution over 30 minutes. However, when significant expansion has occurred due to interstitial edema developed during surgery, the matrix loses much of its elastic quality, causing the distributed fluid to remain in the interstitial tissue for a prolonged period. Consistent with this speculation, Hahn et al. [44] observed slower return of Ringer's acetate from the peripheral fluid compartment to the plasma with high than with low infusion rates in healthy volunteers. A lower than $10 \mathrm{ml} / \mathrm{min}$ infusion rate of crystalloids should be recommended in clinical practice [44].

The anatomical interstitial space measured using a small tracer molecule is approximately $11 \mathrm{~L}$ in adults. Volume kinetics, however, measures only the volume that can be expanded by IV fluids (i.e., physiological interstitial space) and does not include nonexpandable interstitial spaces limited by rigid structures such as bone (brain, marrow) or fibrous capsules (liver, spleen, and kidney). Consequently, physiological interstitial space is 7-8 L, which is twice as large as the plasma volume. One-third of the infused fluid should remain in the plasma and two-thirds in the interstitium [8]. Consequently, a replacement of two times the amount of hemorrhaged blood volume with crystalloids appears reasonable, contrary to the common recommendation of three to four times volume replacement with crystalloids.

Spinal anesthesia did not affect the fluid kinetics in a clinical study using acetated Ringer's solution [45]. However, dis- tribution of infused fluid is delayed and efficacy is enhanced during onset of hypotension in spinal anesthesia as in general anesthesia; the $\mathrm{Tl} / 2$ was prolonged four-fold in patients whose mean arterial pressure was reduced by $20 \%$ after spinal anesthesia [46].

\section{IDEAL FLUID TYPE DURING SURGERY AND INTENSIVE CARE}

IV fluids are categorized into two classes: crystalloids, which contain electrolytes in water that freely cross the EGL and capillary wall into the interstitium, and colloids, which comprise macromolecules confined in the vascular space by the EGL and capillary walls.

\section{Crystalloids}

Crystalloids are further categorized into unbalanced (e.g., saline) and balanced (e.g., Ringer's lactate, Ringer's acetate, and Plasma-Lyte) (Table 2). Among crystalloids, saline is the most commonly used worldwide. Saline contains a chloride concentration $50 \%$ higher than that of plasma and a strong ion difference of zero (unbalanced). Rapid administration of large amounts of saline produces hyperchloremic metabolic acidosis $[20,21]$. Saline also undesirably affects renal function. Infusion of $2 \mathrm{~L}$ of saline over 1-2 hours in healthy volunteers reduced glomerular filtration rate and renal blood flow [47]. It has been shown that the use of saline, as compared to balanced crystalloids, is consistently associated with postoperative complications after open abdominal surgery [48]. Furthermore, use of saline has been associated with higher rates of compli- 
Table 2. Tonicity $(\mathrm{m} 0 \mathrm{sm} / \mathrm{L})$ and electrolyte composition $(\mathrm{mEq} / \mathrm{L})$ of plasma and crystalloids

\begin{tabular}{lccccccccr}
\hline Variable & Tonicity & $\mathrm{Na}^{+}$ & $\mathrm{K}^{-}$ & $\mathrm{Cl}^{-}$ & $\mathrm{Ca}^{2+}$ & $\mathrm{HCO}_{3}^{-}$ & Lactate & Acetate & $\mathrm{SID}$ \\
\hline Plasma & $280-295$ & $135-145$ & $3.5-5.2$ & $95-105$ & $4.4-5.2$ & $22-26$ & 1 & 0 & $\sim 42$ \\
Saline & 308 & 154 & 0 & 154 & 0 & 0 & 0 & 0 \\
Ringer's lactate $_{\text {Ringer's acetate }}^{\mathrm{a}}$ & 273 & 130 & 4 & 109 & 3 & 0 & 28 & 0 & 28 \\
Plasma-Lyte $^{b}$ & 270 & 130 & 4 & 110 & 4 & 0 & 0 & 24 & 29 \\
\hline
\end{tabular}

SID: strong ion difference in vivo.

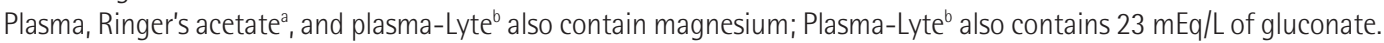

cations, including AKI and in-hospital mortality, in observational studies among critically ill adults [14,24]. Mechanisms underlying renal injury associated with hyperchloremia may include reduced renal blood flow due to afferent arteriolar vasoconstriction, inflammation, and edema [39]. Moreover, renal fluid clearance is $35 \%-40 \%$ lower for saline than for Ringer's acetate or Ringer's lactate, showing less pronounced diuresis [36]. Although balanced crystalloids are considered to be the first choice of IV fluid in modern clinical practice, saline is reserved for special indications, such as hyponatremia or hypochloremic metabolic alkalosis associated with vomiting. Saline may also be used for irrigation and as a vehicle for IV administration of drugs.

Balanced solutions are crystalloids that contain electrolyte compositions closer to that of ECF. The solutions are the mainstay of fluid administration in perioperative and critical care settings and should be used when saline is not indicated. Ringer's lactate substitutes a portion of chloride content with L-lactate buffer, providing a more physiologic chloride concentration. However, Ringer's lactate is slightly hypotonic relative to the plasma and may worsen cerebral edema and increase intracranial pressure in patients with brain injury [25]. Ringer's lactate may not be a choice in patients with liver hypoperfusion or insufficiency since lactate metabolism entirely depends on preserved liver function. To compensate for this drawback, in Ringer's acetate the L-lactate is replaced with acetate, which is rapidly oxidized by the liver, muscle, and heart to yield $\mathrm{HCO}_{3}{ }^{-}$. To date, evidence of acetate toxicity after volume resuscitation has not been reported. Among commercial crystalloids, Plasma-Lyte is the closest to balanced both acid-base and tonicity perspectives. It contains stable organic anionic buffers of acetate and gluconate. In addition, Plasma-Lyte does not contain $\mathrm{Ca}^{2+}$ and thus is used for dilution of packed red blood cells prior to transfusion. Moreover, Plasma-Lyte may be the best option for patients with diabetic ketoacidosis in which correction of severe metabolic acidosis and fluid intervention is indicated [49].

\section{Colloids}

Colloids are crystalloid electrolyte solutions with macromolecules such as albumin and synthetic colloids (e.g., HES, gelatin, and dextran). However, the relatively higher cost and occasional complications may limit their use. Albumin (67 kDa) is the reference colloid suspended in saline and may be used either for correction of hypoalbuminemia or hypovolemia and for resuscitation of early septic patients. Albumin has the potential to preserve glycocalyx and renal function in critically ill patients [18]. Thus, the Surviving Sepsis Campaign advises consideration of albumin in addition to crystalloids for initial volume resuscitation when patients require substantial amounts of crystalloids [50].

HES solutions are the most commonly used colloids worldwide. However, high-molecular-weight preparations (e.g., hetastarch, pentastarch) were associated with coagulopathy and AKI in sepsis, resulting in their disuse [51]. Third-generation HES (tetrastarch) has reduced concentration (6\%) with a molecular weight of $130 \mathrm{kDa}$ and molar substitution ratio of 0.38 0.45 . These solutions have been used to optimize hemodynamics in critical care patients and in individuals undergoing major surgery, particularly as a component of goal-directed fluid therapy to prevent excessive positive fluid balance [52].

Colloids may be warranted when crystalloid replacement exceeds 3-4 L prior to transfusion in patients with severe intravascular fluid deficit due to acute hemorrhage [53]. Colloids persist longer in the intravascular space, hindering development of edema. Thus, combined initial use of $3 \mathrm{~L}$ of crystalloids with colloids top-up appears to represent a reasonable approach, especially in patients requiring large fluid volumes.

\section{OPTIMAL AMOUNT OF FLUID}

Fluid management has evolved significantly over the last 10 years as approaches such as laparoscopic surgery and enhanced recovery pathways after surgery have become popular. In 
addition, knowledge of fluid kinetics and the role of EGL in microvascular fluid exchange have been accumulated. Both insufficient and excessive amounts of fluid may have a negative impact on patient outcomes. Hypovolemia leads to decreased volume of circulating blood and oxygen delivery to organs and peripheral tissues, causing organ dysfunction, whereas fluid overload causes tissue edema with increased risk of postoperative pulmonary complications, wound infections, and organ dysfunction [54-56].

Patients undergoing major abdominal surgery have often been administered a large volume of crystalloids during and after surgery because of preoperative fasting and third-space loss. Surgical patients are fasted for too long from midnight before the surgery. Current guidelines recommend oral intake of clear fluids or carbohydrate drinks up to 2 hours prior to surgery, reducing the need for supplemental fluid. The extent of the third space has recently been refuted [57]. Furthermore, the rates of distribution and elimination of infused fluid are significantly delayed under general anesthesia, stress, or dehydration, thereby enhancing fluid efficiency [9]. These concepts may underlie a shift of the current fluid strategy toward more restrictive fluid amounts.

Perioperative fluid loss consisting of diuresis, insensible perspiration, evaporation from the wound, and accumulation in the traumatized tissue accounts for no more than $1-1.5 \mathrm{ml} / \mathrm{kg} / \mathrm{hr}$. However, general anesthesia inhibits the autonomic control of the cardiovascular system, possibly inducing a type of distributive shock. Blood is directed away from the gastrointestinal tract, an early trouble-spot for ischemia. Infusion of as little as $2 \mathrm{ml} / \mathrm{kg} / \mathrm{hr}$ of crystalloids during surgery is associated with a higher incidence of nausea; however, additional crystalloids relieve the problem [12]. Therefore, the current recommendation is to administer $3-5 \mathrm{ml} / \mathrm{kg} / \mathrm{hr}$ of crystalloids during ongoing surgery, although more fluid is necessary in situations where blood loss is not minimal. A volume kinetic simulation of crystalloid infusion in this range shows a plasma volume expansion of 50-170 $\mathrm{ml}$ at 3 hours after surgery [58].

The restrictive strategy aiming for "zero-balance" based on intraoperative measurement of lost blood and fluid and on body weight postoperatively is easily implemented and was shown to reduce postoperative complications in patients undergoing colorectal surgery [43]. When administered in excess amounts, crystalloids are preferentially distributed to the interstitium of the subcutis, the gut, and the lungs. Accordingly, restricted use of fluid is the standard practice for patients undergoing major abdominal surgery [43,57], esophagectomy [59], or pulmonary resection surgery.
However, the Restrictive Versus Liberal Fluid Therapy in Major Abdominal Surgery (RELIEF) trial showed a high incidence of postoperative AKI ( $8.6 \%$ vs. $5.0 \%, \mathrm{P}<0.001)$ despite similar survival rates between groups [60]. The restrictive group received a $5 \mathrm{ml} / \mathrm{kg}$ bolus at anesthesia induction, followed by intraoperative crystalloid infusion at a rate of $5 \mathrm{ml} / \mathrm{kg} / \mathrm{hr}$ (approximately $1.7 \mathrm{~L}$ infusion intraoperatively); the liberal group received a $10-\mathrm{ml} / \mathrm{kg}$ bolus at induction, followed by an intraoperative rate of $8 \mathrm{ml} / \mathrm{kg} / \mathrm{hr}$ (approximately $3 \mathrm{~L}$ infusion), which more closely resembled the restrictive group in the randomized multicenter trial by Brandstrup et al. [43]. Myles et al. [61] performed a post hoc analysis of data from RELIEF to evaluate whether intraoperative oliguria is an independent predictor of AKI. They found that oliguria, defined as urine output $<0.5$ $\mathrm{ml} / \mathrm{kg} / \mathrm{hr}$, was associated with postoperative AKI. These results are in conflict with a recent trend toward a more restrictive fluid approach during major surgery, indicating that aiming for "zero fluid balance" is too restrictive, and a somewhat liberal approach may be needed. Therefore, evidence-based practices in nonthoracic surgeries are moving away from a restrictive fluid strategy toward approaches directed to maintain a euvolemic state.

Goal-directed fluid therapy is a method of optimizing fluid and hemodynamic status for at-risk patients, using monitors to predict which patients will show hemodynamic improvement after fluid administration (fluid responsiveness). Recently, this individualized fluid therapy based on objective feedback regarding patient fluid responsiveness was shown to improve patient outcomes. To estimate hemodynamic responses, static and dynamic measures have been used. Early static measures (e.g., central venous pressure, pulmonary artery occlusion pressure, global end-diastolic volume, and inferior vena cava diameter) poorly predict fluid responsiveness. Therefore, the measures are no longer recommended for routine use. Instead, dynamic measures in which the effects on cardiac output in response to changes in cardiac preload are observed, either by changes during the respiratory cycle (e.g., pulse pressure variation, systolic pressure variation, and stroke volume variation) or evoked by certain maneuvers (e.g., passive leg raise to $30^{\circ}$, end-expiratory occlusion test for 15 seconds, or small fluid bolus of $3 \mathrm{ml} / \mathrm{kg}$ ), are currently favored [62].

In contrast, for relatively low-risk patients undergoing lowrisk or ambulatory surgery, a liberal fluid strategy of $20-30 \mathrm{ml} / \mathrm{kg}$ (e.g., $2 \mathrm{~L}$ over 30 minutes in average adult) was shown to reduce postoperative nausea, vomiting, and pain [13]. This strategy is also considered favorable for patients undergoing laparoscopic cholecystectomy [63] or total knee replacement [64]. 
In thoracic surgery, fluid restriction has historically been advocated with the aim of decreasing interstitial hydrostatic pressure, limiting the incidence of acute lung injury. However, large randomized controlled trials in which fluid management strategies are evaluated in thoracic surgery are lacking. Wu et al. [65] recently performed a single-center retrospective analysis to assess the effects of intraoperative fluid therapy on postoperative pulmonary complications in 446 patients undergoing a minimally invasive lobectomy. The cohort was classified into four groups (restrictive, moderate, moderately liberal, and liberal) based on intraoperative fluid infusion rate. They found the incidence of postoperative pneumonia and composite pulmonary complications to be lowest in the moderate group (9.4-11.8 ml/kg/hr), along with the incidence of postoperative AKI and length of hospital stay comparable.

\section{Fluid Management in Critically III Patients}

Microcirculatory alterations are frequently observed in critically ill patients who suffer from sepsis or major trauma and individuals undergoing major surgery [55]. For appropriate fluid resuscitation in these patients, clinicians must evaluate not only the pathophysiology underlying the hemodynamic instability, phase of fluid therapy $[56,66]$, and expected fluid responsiveness [62], but also the outcomes from clinical trials [67].

In sepsis, goal-directed, early, aggressive fluid resuscitation has been the mainstay since Rivers et al. [68] in 2001 demonstrated lower mortality in patients who received goal-directed therapy for 6 hours compared with controls ( 5 vs. $3.5 \mathrm{~L}$ ). With mounting concerns regarding increased mortality associated with a positive fluid balance in critically ill patients [69], three large randomized clinical trials were recently performed to investigate whether large-volume resuscitation is appropriate [70-72]. The results showed lower mortality rate despite the use of lower volume (8.5-9.0 L) during the first 72 hours than that (13.4 L) in the Rivers et al.'s study [68], supporting the hypothesis that overaggressive fluid administration may increase mortality in critically ill patients $[55,69]$. In contrast, the infused volume (4.1-5.0 L) during the first 6 hours in the trials was similar to that (5 L) in the Rivers et al's study [68]. This finding is in agreement with clinical trials that showed the importance of fluid resuscitation in the initial phase when hemodynamics are unstable [67].

Based on Rivers et al. [68] and subsequent trials [70-72], international guidelines for sepsis management recommend rapid infusion of $30 \mathrm{ml} / \mathrm{kg}$ of crystalloids as a 1-hour bundle [73], followed by ongoing fluid administration for patients who continue to show fluid responsiveness [50]. Likewise, Casey et al. [67] suggested a resuscitation strategy to administer 2-3 L of balanced crystalloids for initial resuscitation of hypovolemic or distributive shock and additional fluid based on hemodynamic responsiveness. Furthermore, current fluid strategies in critically ill patients are changing toward more restrictive use of fluids, with early administration of vasopressors to achieve blood pressure goals [55]. In a recent study in patients with severe sepsis and septic shock, the total fluid volume infused within 72 hours was significantly reduced to $71 \mathrm{ml} / \mathrm{kg}$ (approximately $5 \mathrm{~L}$ for an average weight of $70 \mathrm{~kg}$ ) with the aid of vasopressors without affecting mortality or organ failure [74]. Another study involving similar septic patients advocated an initial volume of balanced crystalloids as low as $20 \mathrm{ml} / \mathrm{kg}$, followed by subsequent administration based on fluid responsiveness [75].

Regarding the type of resuscitation fluids, new evidence indicates improved patient outcomes with use of balanced crystalloids compared with saline in most critically ill patients $[10,14,48]$. In contrast, even 6\% HES 130/0.4-0.42 was associated with increased risk of AKI or death compared with crystalloids in septic [26] and acutely ill [27] patients. Therefore, the current trend is to choose balanced crystalloids over saline or synthetic colloids for volume resuscitation. In 2013, the U.S. Food and Drug Administration recommended against the use of HES in critically ill patients.

\section{ADVERSE EFFECTS OF FLUIDS}

The infused fluid leaks and accumulates dose-dependently in the interstitium, even in healthy individuals. Tissue edema occurs only when the capacity of the lymphatic system to drain off this volume is overwhelmed, leading to organ dysfunction by impairing the diffusion of oxygen and metabolites and reducing tissue perfusion. Adverse effects of crystalloids are associated with their preferential distribution to the subcutis, gut, and lungs. When more than $2 \mathrm{~L}$ is administered, the gastrointestinal recovery time is delayed by 2 days [76]. Infusion of even larger amounts of crystalloids during open abdominal surgery causes impaired wound healing, pulmonary edema, pneumonia, and pitting edema in the leg $[53,54]$.

Adverse effects of colloids include anaphylactic reactions $(0.058 \%$ for starches), AKI $[26,27]$, coagulopathy, dilutional anemia, and colloid edema $[53,54]$. Coagulation is impaired when the induced hemodilution reaches $40 \%$ for both crystalloids and colloids. Although both fluids induce edema, the pathophysiology may differ. Infused colloids other than albu- 
min probably undergo capillary leakage, and extravasated colloid molecules attract fluid because the plasma volume expansion effect is much shorter than the $\mathrm{T} 1 / 2$ of the respective macromolecules in the body [26]. Alternatively, colloids may displace intravascular crystalloids into interstitial space because their distribution is confined to approximately $2.3 \mathrm{~L}$ (average adult male) of the plasma space. This speculation was substantiated in a previous study in which the infusion of Ringer's acetate 2 hours after HES in volunteers was followed by a $50 \%$ greater peripheral accumulation of fluid compared with infusion of Ringer's acetate alone [77].

In critically ill patients whose EGL is degraded, the turnover of colloids and crystalloids is accelerated, resulting in decreased efficiency and T1/2 [17-19]. An overaggressive fluid therapy may then augment glycocalyx degradation $[18,78]$ and cause profound interstitial edema in vital organs, resulting in renal, hepatic, and cardiac dysfunction. Increased extravascular lung water is particularly lethal, leading to iatrogenic salt water drowning [69]. Hippensteel et al. [78] demonstrated that the volume of IV fluids administered during resuscitation in patients with septic shock was independently associated with degree of glycocalyx degradation, being causally related to inhospital mortality.

\section{CONCLUSION}

The turnover of crystalloids shows a significant variability (more than 10-fold) that is influenced by general anesthesia and physiological conditions such as stress, dehydration, and inflammation. The type and amount of fluid administered may affect patient outcomes. A better understanding of the fluid kinetics and characteristics of each fluid under different conditions will help refine the optimal application of fluid therapy. Fluids should be managed as drugs, with the type and dosage adapted to each patient's individual ongoing needs and tolerance.

\section{CONFLICT OF INTEREST}

No potential conflict of interest relevant to this article was reported.

\section{ACKNOWLEDGMENTS}

The authors would like to thank Dr. JongUn Lee (Department of Physiology, Chonnam National University Medical School), Dr. Choonhak Lim (Department of Anesthesiology and Pain
Medicine, Korea University Anam Hospital) and Dr. Sunggin Hong (Department of Anesthesiology and Pain Medicine, The Catholic University of Korea) for their thoughtful comments and careful review of this manuscript.

\section{ORCID}

Dongho Kang https://orcid.org/0000-0002-5299-6861

Kyung Yeon Yoo https://orcid.org/0000-0002-6509-4904

\section{AUTHOR CONTRIBUTIONS}

Conceptualization: KYY. Data curation: DK. Formal analysis: KYY. Project administration: KYY. Visualization: DK. Writing original draft, review \& editing: all authors.

\section{REFERENCES}

1. Connolly CM, Kramer GC, Hahn RG, Chaisson NF, Svensén $\mathrm{CH}$, Kirschner RA, et al. Isoflurane but not mechanical ventilation promotes extravascular fluid accumulation during crystalloid volume loading. Anesthesiology 2003;98:670-81.

2. Zdolsek J, Li Y, Hahn RG. Detection of dehydration by using volume kinetics. Anesth Analg 2012;115:814-22.

3. Drobin D, Hahn RG. Volume kinetics of Ringer's solution in hypovolemic volunteers. Anesthesiology 1999;90:81-91.

4. Hahn RG. Arterial pressure and the rate of elimination of crystalloid fluid. Anesth Analg 2017;124:1824-33.

5. Hahn RG, Lyons G. The half-life of infusion fluids: an educational review. Eur J Anaesthesiol 2016;33:475-82.

6. Olsson J, Svensén CH, Hahn RG. The volume kinetics of acetated Ringer's solution during laparoscopic cholecystectomy. Anesth Analg 2004;99:1854-60.

7. Hahn RG. Why are crystalloid and colloid fluid requirements similar during surgery and intensive care? Eur J Anaesthesiol 2013;30:515-8.

8. Hahn RG. Why crystalloids will do the job in the operating room. Anaesthesiol Intensive Ther 2014;46:342-9.

9. Hahn RG. Volume kinetics for infusion fluids. Anesthesiology 2010;113:470-81.

10. Semler MW, Self WH, Wanderer JP, Ehrenfeld JM, Wang L, Byrne DW, et al. Balanced crystalloids versus saline in critically ill adults. N Engl J Med 2018;378:829-39.

11. Self WH, Semler MW, Wanderer JP, Wang L, Byrne DW, Collins SP, et al. Balanced crystalloids versus saline in noncritically ill adults. N Engl J Med 2018;378:819-28.

12. Apfel CC, Meyer A, Orhan-Sungur M, Jalota L, Whelan RP, Ju- 
kar-Rao S. Supplemental intravenous crystalloids for the prevention of postoperative nausea and vomiting: quantitative review. Br J Anaesth 2012;108:893-902.

13. Holte K, Kehlet H. Compensatory fluid administration for preoperative dehydration: does it improve outcome? Acta Anaesthesiol Scand 2002;46:1089-93.

14. Raghunathan K, Bonavia A, Nathanson BH, Beadles CA, Shaw $\mathrm{AD}$, Brookhart MA, et al. Association between initial fluid choice and subsequent in-hospital mortality during the resuscitation of adults with septic shock. Anesthesiology 2015;123:1385-93.

15. Alphonsus CS, Rodseth RN. The endothelial glycocalyx: a review of the vascular barrier. Anaesthesia 2014;69:777-84.

16. Kolsen-Petersen JA. The endothelial glycocalyx: the great luminal barrier. Acta Anaesthesiol Scand 2015;59:137-9.

17. Chappell D, Jacob M. Role of the glycocalyx in fluid management: small things matter. Best Pract Res Clin Anaesthesiol 2014;28:227-34.

18. Uchimido R, Schmidt EP, Shapiro NI. The glycocalyx: a novel diagnostic and therapeutic target in sepsis. Crit Care 2019;23: 16.

19. Fleck A, Raines G, Hawker F, Trotter J, Wallace PI, Ledingham IM, et al. Increased vascular permeability: a major cause of hypoalbuminaemia in disease and injury. Lancet 1985;1:781-4.

20. McFarlane C, Lee A. A comparison of Plasmalyte 148 and $0.9 \%$ saline for intra-operative fluid replacement. Anaesthesia 1994; 49:779-81.

21. Scheingraber S, Rehm M, Sehmisch C, Finsterer U. Rapid saline infusion produces hyperchloremic acidosis in patients undergoing gynecologic surgery. Anesthesiology 1999;90:126570.

22. McLean DJ, Shaw AD. Intravenous fluids: effects on renal outcomes. Br J Anaesth 2018;120:397-402.

23. Semler MW, Rice TW. Saline is not the first choice for crystalloid resuscitation fluids. Crit Care Med 2016;44:1541-4.

24. Yunos NM, Bellomo R, Glassford N, Sutcliffe H, Lam Q, Bailey M. Chloride-liberal vs. chloride-restrictive intravenous fluid administration and acute kidney injury: an extended analysis. Intensive Care Med 2015;41:257-64.

25. Boer C, Bossers SM, Koning NJ. Choice of fluid type: physiological concepts and perioperative indications. Br J Anaesth 2018;120:384-96.

26. Haase N, Perner A, Hennings LI, Siegemund M, Lauridsen B, Wetterslev M, et al. Hydroxyethyl starch 130/0.38-0.45 versus crystalloid or albumin in patients with sepsis: systematic review with meta-analysis and trial sequential analysis. BMJ 2013;346:f839.

27. Gattas DJ, Dan A, Myburgh J, Billot L, Lo S, Finfer S, et al. Fluid resuscitation with $6 \%$ hydroxyethyl starch (130/0.4 and 130/ 0.42 ) in acutely ill patients: systematic review of effects on mortality and treatment with renal replacement therapy. Intensive Care Med 2013;39:558-68.

28. Kammerer T, Brettner F, Hilferink S, Hulde N, Klug F, Pagel JI, et al. No differences in renal function between balanced $6 \%$ hydroxyethyl starch (130/0.4) and 5\% albumin for volume replacement therapy in patients undergoing cystectomy: a randomized controlled trial. Anesthesiology 2018;128:67-78.

29. Kabon B, Sessler DI, Kurz A; Crystalloid-Colloid Study Team. Effect of intraoperative goal-directed balanced crystalloid versus colloid administration on major postoperative morbidity: a randomized trial. Anesthesiology 2019;130:728-44.

30. Rehm M, Haller M, Orth V, Kreimeier U, Jacob M, Dressel H, et al. Changes in blood volume and hematocrit during acute preoperative volume loading with $5 \%$ albumin or $6 \%$ hetastarch solutions in patients before radical hysterectomy. Anesthesiology 2001;95:849-56.

31. Levick JR, Michel CC. Microvascular fluid exchange and the revised Starling principle. Cardiovasc Res 2010;87:198-210.

32. Starling EH. On the absorption of fluids from the connective tissue spaces. J Physiol 1896;19:312-26.

33. Adamson RH, Lenz JF, Zhang X, Adamson GN, Weinbaum S, Curry FE. Oncotic pressures opposing filtration across nonfenestrated rat microvessels. J Physiol 2004;557(Pt 3):889-907.

34. Woodcock TE, Woodcock TM. Revised Starling equation and the glycocalyx model of transvascular fluid exchange: an improved paradigm for prescribing intravenous fluid therapy. Br J Anaesth 2012;108:384-94.

35. Hall JE. The body fluid compartments: extracellular and intracellular fluids; edema. In: Hall JE, editor. Guyton and Hall textbook of medical physiology. 13th ed. Philadelphia: Elsevier; 2016. p. 305-21.

36. Drobin D, Hahn RG. Kinetics of isotonic and hypertonic plasma volume expanders. Anesthesiology 2002;96:1371-80.

37. Reid F, Lobo DN, Williams RN, Rowlands BJ, Allison SP. (Ab) normal saline and physiological Hartmann's solution: a randomized double-blind crossover study. Clin Sci (Lond) 2003; 104:17-24.

38. Sjöstrand F, Edsberg L, Hahn RG. Volume kinetics of glucose solutions given by intravenous infusion. Br J Anaesth 2001;87: 834-43.

39. Wilcox CS. Regulation of renal blood flow by plasma chloride. J Clin Invest 1983;71:726-35.

40. Hahn RG. The elimination half-life of crystalloid fluid is shorter in female than in male volunteers: a retrospective population kinetic analysis. Biol Sex Differ 2016;7:54. 
41. Lobo DN, Stanga Z, Aloysius MM, Wicks C, Nunes QM, Ingram $\mathrm{KL}$, et al. Effect of volume loading with 1 liter intravenous infusions of $0.9 \%$ saline, $4 \%$ succinylated gelatine (Gelofusine) and $6 \%$ hydroxyethyl starch (Voluven) on blood volume and endocrine responses: a randomized, three-way crossover study in healthy volunteers. Crit Care Med 2010;38:464-70.

42. Holte K, Hahn RG, Ravn L, Bertelsen KG, Hansen S, Kehlet H. Influence of "liberal" versus "restrictive" intraoperative fluid administration on elimination of a postoperative fluid load. Anesthesiology 2007;106:75-9.

43. Brandstrup B, Tønnesen H, Beier-Holgersen R, Hjortsø E, Ørding $\mathrm{H}$, Lindorff-Larsen $\mathrm{K}$, et al. Effects of intravenous fluid restriction on postoperative complications: comparison of two perioperative fluid regimens: a randomized assessor-blinded multicenter trial. Ann Surg 2003;238:641-8.

44. Hahn RG, Drobin D, Zdolsek J. Distribution of crystalloid fluid changes with the rate of infusion: a population-based study. Acta Anaesthesiol Scand 2016;60:569-78.

45. Hahn RG, Lindahl CC, Drobin D. Volume kinetics of acetated Ringer's solution during experimental spinal anaesthesia. Acta Anaesthesiol Scand 2011;55:987-94.

46. Ewaldsson CA, Hahn RG. Volume kinetics of Ringer's solution during induction of spinal and general anaesthesia. $\mathrm{Br} \mathrm{J}$ Anaesth 2001;87:406-14.

47. Chowdhury AH, Cox EF, Francis ST, Lobo DN. A randomized, controlled, double-blind crossover study on the effects of 2-L infusions of $0.9 \%$ saline and plasma-lyte ${ }^{\circledR} 148$ on renal blood flow velocity and renal cortical tissue perfusion in healthy volunteers. Ann Surg 2012;256:18-24.

48. Shaw AD, Bagshaw SM, Goldstein SL, Scherer LA, Duan M, Schermer CR, et al. Major complications, mortality, and resource utilization after open abdominal surgery: $0.9 \%$ saline compared to Plasma-Lyte. Ann Surg 2012;255:821-9.

49. Chua HR, Venkatesh B, Stachowski E, Schneider AG, Perkins $\mathrm{K}$, Ladanyi S, et al. Plasma-Lyte 148 vs $0.9 \%$ saline for fluid resuscitation in diabetic ketoacidosis. J Crit Care 2012;27:138-45.

50. Rhodes A, Evans LE, Alhazzani W, Levy MM, Antonelli M, Ferrer R, et al. Surviving Sepsis Campaign: International Guidelines for Management of Sepsis and Septic Shock: 2016. Intensive Care Med 2017;43:304-77.

51. Brunkhorst FM, Engel C, Bloos F, Meier-Hellmann A, Ragaller $\mathrm{M}$, Weiler $\mathrm{N}$, et al. Intensive insulin therapy and pentastarch resuscitation in severe sepsis. N Engl J Med 2008;358:125-39.

52. Joosten A, Delaporte A, Ickx B, Touihri K, Stany I, Barvais L, et al. Crystalloid versus colloid for intraoperative goal-directed fluid therapy using a closed-loop system: a randomized, double-blinded, controlled trial in major abdominal surgery. An- esthesiology 2018;128:55-66.

53. Hahn RG. Adverse effects of crystalloid and colloid fluids. Anaesthesiol Intensive Ther 2017;49:303-8.

54. Reuter DA, Chappell D, Perel A. The dark sides of fluid administration in the critically ill patient. Intensive Care Med 2018; 44:1138-40.

55. Vincent JL. Fluid management in the critically ill. Kidney Int 2019;96:52-7.

56. Brandstrup B, Svensen C, Engquist A. Hemorrhage and operation cause a contraction of the extracellular space needing replacement: evidence and implications?: a systematic review. Surgery 2006;139:419-32.

57. Varadhan KK, Lobo DN. A meta-analysis of randomised controlled trials of intravenous fluid therapy in major elective open abdominal surgery: getting the balance right. Proc Nutr Soc 2010;69:488-98.

58. Ewaldsson CA, Hahn RG. Kinetics and extravascular retention of acetated ringer's solution during isoflurane or propofol anesthesia for thyroid surgery. Anesthesiology 2005;103: 460-9.

59. Glatz T, Kulemann B, Marjanovic G, Bregenzer S, Makowiec F, Hoeppner J. Postoperative fluid overload is a risk factor for adverse surgical outcome in patients undergoing esophagectomy for esophageal cancer: a retrospective study in 335 patients. BMC Surg 2017;17:6.

60. Myles PS, Bellomo R, Corcoran T, Forbes A, Peyton P, Story D, et al. Restrictive versus liberal fluid therapy for major abdominal surgery. N Engl J Med 2018;378:2263-74.

61. Myles PS, McIlroy DR, Bellomo R, Wallace S. Importance of intraoperative oliguria during major abdominal surgery: findings of the restrictive versus liberal fluid therapy in major abdominal surgery trial. Br J Anaesth 2019;122:726-33.

62. Jalil BA, Cavallazzi R. Predicting fluid responsiveness: a review of literature and a guide for the clinician. Am J Emerg Med 2018;36:2093-102.

63. Holte K, Klarskov B, Christensen DS, Lund C, Nielsen KG, Bie $\mathrm{P}$, et al. Liberal versus restrictive fluid administration to improve recovery after laparoscopic cholecystectomy: a randomized, double-blind study. Ann Surg 2004;240:892-9.

64. Holte K, Kristensen BB, Valentiner L, Foss NB, Husted H, Kehlet $H$. Liberal versus restrictive fluid management in knee arthroplasty: a randomized, double-blind study. Anesth Analg 2007; 105:465-74.

65. Wu Y, Yang R, Xu J, Rusidanmu A, Zhang X, Hu J. Effects of intraoperative fluid management on postoperative outcomes after lobectomy. Ann Thorac Surg 2019;107:1663-9.

66. Malbrain ML, van Regenmortel N, Saugel B, De Tavernier B, 
van Gaal PJ, Joannes-Boyau O, et al. Principles of fluid management and stewardship in septic shock: it is time to consider the four D's and the four phases of fluid therapy. Ann Intensive Care 2018;8:66.

67. Casey JD, Brown RM, Semler MW. Resuscitation fluids. Curr Opin Crit Care 2018;24:512-8.

68. Rivers E, Nguyen B, Havstad S, Ressler J, Muzzin A, Knoblich $B$, et al. Early goal-directed therapy in the treatment of severe sepsis and septic shock. N Engl J Med 2001;345:1368-77.

69. Marik PE. Iatrogenic salt water drowning and the hazards of a high central venous pressure. Ann Intensive Care 2014;4:21.

70. Mouncey PR, Osborn TM, Power GS, Harrison DA, Sadique MZ, Grieve RD, et al. Trial of early, goal-directed resuscitation for septic shock. N Engl J Med 2015;372:1301-11.

71. ARISE Investigators; ANZICS Clinical Trials Group, Peake SL, Delaney A, Bailey M, Bellomo R, et al. Goal-directed resuscitation for patients with early septic shock. N Engl J Med 2014; 371:1496-506.

72. ProCESS Investigators, Yealy DM, Kellum JA, Huang DT, Barnato AE, Weissfeld LA, et al. A randomized trial of protocol- based care for early septic shock. N Engl J Med 2014;370:168393.

73. Levy MM, Evans LE, Rhodes A. The Surviving Sepsis Campaign Bundle: 2018 update. Intensive Care Med 2018;44:925-8.

74. Corl KA, Prodromou M, Merchant RC, Gareen I, Marks S, Banerjee $\mathrm{D}$, et al. The restrictive IV fluid trial in severe sepsis and septic shock (RIFTS): a randomized pilot study. Crit Care Med 2019;47:951-9.

75. Brown RM, Semler MW. Fluid management in sepsis. J Intensive Care Med 2019;34:364-73.

76. Li Y, He R, Ying X, Hahn RG. Ringer's lactate, but not hydroxyethyl starch, prolongs the food intolerance time after major abdominal surgery; an open-labelled clinical trial. BMC Anesthesiol 2015;15:72.

77. Hahn RG, Bergek C, Gebäck T, Zdolsek J. Interactions between the volume effects of hydroxyethyl starch 130/0.4 and Ringer's acetate. Crit Care 2013;17:R104.

78. Hippensteel JA, Uchimido R, Tyler PD, Burke RC, Han X, Zhang $\mathrm{F}$, et al. Intravenous fluid resuscitation is associated with septic endothelial glycocalyx degradation. Crit Care 2019;23:259. 